\title{
Changing the paradigm of cervical cancer prevention through introduction of HPV-testing: evaluation of the implementation process of the Jujuy Demonstration Project in Argentina
}

Silvina Arrossi ( $\square$ silviarrossi2020@gmail.com )

Consejo Nacional de Investigaciones Cientificas y Tecnicas Centro Argentino de Informacion Cientifica y Tecnologica

Melisa Paolino

Centro de Estudio de Estado y Sociedad/Consejo Nacional de Investigaciones Cientificas y Tecnicas

Rosa Laudi

Hospital Ramos Mejía

Laura Thouyaret

Programa Nacional de Prevención de Cáncer Cérvicouterino/Instituto Nacional del Cáncer (Argentina)

\section{Research article}

Keywords: cervical screening, implementation, public health, Argentina

Posted Date: December 5th, 2019

DOI: https://doi.org/10.21203/rs.2.18254/v1

License: (c) (1) This work is licensed under a Creative Commons Attribution 4.0 International License.

Read Full License

Version of Record: A version of this preprint was published at ecancermedicalscience on March 4th, 2021. See the published version at https://doi.org/10.3332/ecancer.2021.1199. 


\section{Abstract}

Background The Jujuy Demonstration Project (JDP) was a four-year implementation project (2011-2014) to develop, implement and evaluate the programmatic components of an HPV-based screening program in Argentina. The aim of this paper is present a qualitative evaluation of the context and implementation process of JDP.

Methods We used an adaptation of the Health System Framework (HSF), which includes contextual interconnected factors that are considered key drivers for successful health interventions. We reviewed Secondary Documents, which included program reports, information sheets, power point presentations, and minutes of meetings and management round-tables. We also carried out semi-structured interviews to key informants to explore their views about technology acceptability.

Results Key components of JDP implementation process were high level of political support and consensus among stakeholders, the demonstrated effectiveness of the technology and its acceptability by health authorities and providers, funding of tests and diagnosis/treatment services, implementation of an information system for monitoring and evaluation, and the reorganization of the network of screening diagnosis and treatment services.

Conclusion This analysis has made explicit the policy context in which the JDP was implemented, and system components that were key for the demonstrated effectiveness of the strategy. Such analyses provide useful insights into core components of HPV-testing implementation that are needed to guarantee its potential effectiveness to reduce cervical cancer incidence and mortality .

\section{Background}

Cervical cancer is almost completely preventable with existing knowledge and technology. Although the disease may be controlled with cytology-based screening ${ }^{1}$ performed in an organized program, ${ }^{2}$ these programs have been difficult to implement in the health systems of low and middle income countries. ${ }^{3-4}$ In the last decades, Human Papilloma Virus (HPV) testing was developed as an alternative screening method. HPV-test is highly sensitive and effective to prevent cervical cancer incidence and mortality. ${ }^{5}$ In addition, HPV-testing allows for sample self-collection, which has proved effective in increasing screening uptake. ${ }^{6,7}$ All these features have made HPV-testing the preferred tool for cervical cancer screening. In combination with HPV vaccination, HPV-testing appears as a technology that could make a major contribution to the elimination of cervical cancer. ${ }^{8}$

In programmatic contexts, success of HPV-testing will depend on the same factors that have affected effectiveness of cytology-based screening ${ }^{9}$ the existence of a national policy; the adherence of the medical community to algorithm and protocols; availability of economic/technical/human resources; development of information/monitoring systems; high coverage/ treatment levels; and a good quality network of diagnosis and treatment. Thus, low-middle income settings, for HPV-testing to be effective 
has to be introduced in the context of a major system change, i.e. involving changes at all levels of the health system and stakeholders, and program and services ' reorganization. ${ }^{10}$ Otherwise, HPV-based screening programs will very probably not be able to reproduce the level of effectiveness obtained in controlled trials.

In Argentina, HPV-testing as primary screening was introduced in 2012 through the Jujuy Demonstration Project (JDP) ${ }^{11}$, a 4-year population-based study led by the Argentinian National Cancer Institute, done during 2011-14 to evaluate large-scale programmatic introduction of HPV testing. Jujuy, the province chosen for the demonstration project had high cervical cancer mortality (11.8 per 100000 in 2008-10 $)^{11}$; a situational analysis done in $2007^{12}$ showed that in Jujuy, cervical screening coverage was low, information systems were unreliable, information on follow-up and treatment was missing, and providers had low adherence to programmatic norms and recommendations. Cytology results were read in six laboratories, which processed in total around 22,000 annual samples without quality controls. To give an indication of the scale of the changes, from January 1st 2012, all 300 provincial health care centers stopped doing cytology-based screening and began to offer HPV-testing. Within three years of its implementation, over 49,000 women were HPV-tested, 10\% through self-collection. Compared with what it was achieved during the preceding cytology-based period, HPV-testing more than doubled detection of CIN2 + lesions and, in total, more than 500 women were treated for pre-neoplastic disease. ${ }^{11}$ This increased detection was achieved in the context of program reorganization that included laboratory and referral network reorganization, use of self-collection to increase coverage, and development of mechanisms to assure adherence to guidelines. Findings from the JDP showed that effective screening with HPV testing in real-world programs of middle- income settings is feasible; based on its results, HPVtesting was nationally scaled-up, and by the year 2019 , ten provinces were using the HPV-test as primary screening.

In a complex intervention like the JDP, outcomes are often only partially related to the intervention itself; contextual factors/processes play a key and often dominant role and therefore it is vital to analyze how they influence implementation. In this paper we evaluated the context and implementation process of the JDP. Research on systems is key to provide policy makers and practitioners robust and relevant evidence that takes adequate account of the real-world circumstances in which policies are made, and interventions are implemented. ${ }^{13}$ Combination of this health system analysis with data on effectiveness that has been already published will allow a better understanding of what components are key to reproduce in other settings the programmatic outcomes of the JDP.

\section{Methods}

\section{Setting}

Argentina is a democratic, federal country, integrated by 24 provinces, each of them an autonomous entity responsible for organization, management and financing of the 
provincial health system. Among other activities, the National Ministry of Health provides a regulatory framework for health care, training, and funding for specific programs through nationally and internationally-funded programs. Provincial health ministries may or may not adhere to proposed national health programs or activities; this mainly depending on agreements where responsibilities and funding are negotiated. The province of Jujuy is located in Northwest Argentina and has around 673,000 inhabitants; 85\% of its population lives in urban areas and $32 \%$ of its population are poor. The JDP introduced HPV-testing as primary screening for women aged 30 and over attending the public health sector. Before introduction of HPV-testing cytology was the standard of care for screening. The protocols for HPV-testing have been described elsewhere ${ }^{14}$ and are shown in figure 1. In 2014, HPV self-collection was introduced as a programmatic strategy mainly for under-screened

women: Those without screening in the last 5 years and with public health insurance. ${ }^{15}$ For HPV-self collected tests, HPV+ women should attend health centers to undergo cytology. The final analysis of the JDP impact has been published elsewhere; ${ }^{11}$ key outcomes of the project are summarized in table 1.

\section{Table 1. Jujuy Demonstration Project. Analysis of impact of HPV test implementation}




\begin{tabular}{|c|c|}
\hline OUTCOME & HPV test \\
\hline $\begin{array}{c}\text { \% of women aged 30-64 with public health insurance that } \\
\text { were screened at least once }\end{array}$ & 2.34 (95\% CI: 2.01-2.73) \\
\hline $\begin{array}{c}\text { CIN2+ detection rate among women aged 30+ (Odd ratios } \\
\text { for CC compared to cytology) }\end{array}$ & \\
\hline $\begin{array}{c}\text { \% of women screened with recommended age } \\
\text { \% of over-screening }\end{array}$ & 0.0 \\
\hline \% of positive women with colposcopy & 74.6 \\
\hline \% of women with CIN2+ with registered \\
treatment
\end{tabular}

Source: Adapted from Arrossi et al., 2019, The Lancet Global Health.

* This percentage includes clinician collected tests and self-collected tests for the five-year period 2012-2017.

\section{Data analysis}

A qualitative study was carried out to evaluate the implementation process of JDP. For this we used an adaptation of the Health System Framework (HSF), ${ }^{16-18}$ which includes contextual interconnected factors that are considered key drivers for successful health interventions. ${ }^{19}$ The HSF integrates six building blocks (service delivery, health workforce, information, technology, funding, and stewardship) that influence system performance; they were re-configured to incorporate an organizational dimension, which is a key factor for cervical cancer prevention program effectiveness. ${ }^{20}$ Thus, this adaptation presents four blocks (dimensions) instead of the original six, with specific sub-dimensions (table 2). This 
adaptation of the HSF has already been used for analysis of scaling-up of HPV-self collection in Argentina, ${ }^{15}$ as follows:

1. Stewardship refers to the policy environment in which the implementation of a health strategy is made possible; ${ }^{21}$ sub-dimensions: Policy support, Regulation, Policy guidance, and Accountability.

2. Organizational capacity refers to the capacity of the health system to implement the intervention in all stages of the screening/diagnoses/treatment continuum; subdimensions: Service delivery and health workforce and Information.

3. Health care financing: A good health financing system raises adequate funds for health in ways that ensure people can use needed services; ${ }^{16}$ subdimension: Availability of sustainable funding of the strategy.

4. Technology/strategy: Refers to access to essential medical products/vaccines/

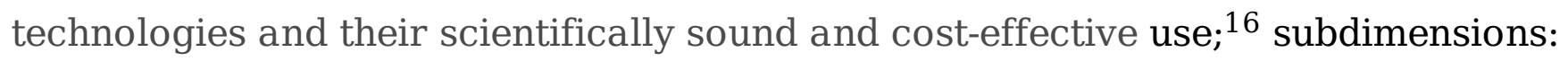
Acceptability and effectiveness and consensus about the value of the technology.

Table 2. Health System Framework. Dimension, Sub-dimension, Categories and Source of data 


\begin{tabular}{|c|c|c|c|}
\hline $\begin{array}{ll}\text { Dimension } & \text { (HSF } \\
\text { building } & \text { block } \\
\text { adaptation) } & \end{array}$ & Sub-dimension & Categories & Source of data \\
\hline \multirow[t]{4}{*}{ Stewardship } & Policy support & $\begin{array}{l}\text { Consensus building, political support and } \\
\text { partnerships for collaboration. }\end{array}$ & $\begin{array}{l}\text { Participant } \\
\text { observation }\end{array}$ \\
\hline & Policy guidance & $\begin{array}{l}\text { Formulating sector strategies. Defining } \\
\text { goals, directions and spending priorities } \\
\text { across services }\end{array}$ & $\begin{array}{l}\text { Participant } \\
\text { observation / } \\
\text { Secondary documents }\end{array}$ \\
\hline & Regulation & Existence of policy guidelines/norms & Secondary Documents \\
\hline & Accountability & Monitoring health system performance & $\begin{array}{l}\text { Participant } \\
\text { observation / } \\
\text { Secondary documents }\end{array}$ \\
\hline \multirow{5}{*}{$\begin{array}{l}\text { Organizational } \\
\text { Capacity }\end{array}$} & \multirow{4}{*}{$\begin{array}{l}\text { Service delivery } \\
\text { and health } \\
\text { workforce }\end{array}$} & Availability of services of screening & Secondary Documents \\
\hline & & Strategies to increase screening coverage & $\begin{array}{l}\text { Participant } \\
\text { observation / } \\
\text { Secondary documents }\end{array}$ \\
\hline & & $\begin{array}{l}\text { Organization and strengthened of referral } \\
\text { network for triage, diagnosis and treatment }\end{array}$ & $\begin{array}{l}\text { Participant } \\
\text { observation / } \\
\text { Secondary documents }\end{array}$ \\
\hline & & Availability of health workforce and training & $\begin{array}{l}\text { Participant } \\
\text { observation / } \\
\text { Secondary documents }\end{array}$ \\
\hline & Information & $\begin{array}{l}\text { Availability and use of health information } \\
\text { system }\end{array}$ & $\begin{array}{l}\text { Health information } \\
\text { system }\end{array}$ \\
\hline \multirow[t]{2}{*}{ Technology/Strategy } & $\begin{array}{l}\text { Evidence based } \\
\text { effectiveness }\end{array}$ & $\begin{array}{l}\text { Consensus about the value of the technology/ } \\
\text { strategy }\end{array}$ & $\begin{array}{l}\text { Scientific evidence } \\
\text { /Secondary } \\
\text { Documents }\end{array}$ \\
\hline & Acceptability & $\begin{array}{l}\text { Perception about advantages of technology } \\
\text { implementation }\end{array}$ & $\begin{array}{l}\text { Semi-structure } \\
\text { interviews }\end{array}$ \\
\hline $\begin{array}{l}\text { Health care } \\
\text { financing }\end{array}$ & Funding & Availability of sustainable funding & Secondary Documents \\
\hline
\end{tabular}

\section{Data collection}

Data sources are shown in table 2. Review of Secondary Documents included program reports, information sheets, power point presentations, and minutes of meetings and management round-tables. Field work notes were taken during researcher participation in project implementation. We also carried out 10 semi-structured interviews to key 
informants to explore their views about technology acceptability: Minister of Health (1), Primary Health Care Director (1); Director of Maternity Health (1); Chief of laboratory (1), Provincial program Coordinator (1) and Health professionals (5). Informed consent was sought prior to each interview.

\section{Data analysis}

Data from semi-structured interviews was transcribed, and secondary documents and field work notes were reviewed. Data coding followed predetermined themes based on HSF dimensions and sub-dimensions. To ensure coding reliability, two researchers independently coded and performed consistency checks. After coding, thematic and content analysis was conducted. ${ }^{22}$ Qualitative data were validated through triangulation of data sources. Method details and FGs results are presented following the Standards for Reporting Implementation Studies: The StaRI checklist for completion. ${ }^{23}$

\section{Results}

\section{Stewardship}

\section{Policy Support}

Consensus building and political support

Consensus building and political support were key activities during the planning phase, carried out in a stepped-wise manner. Four phases were identified in the process: 1. Developing a legitimated proposal to introduce HPV-testing; 2. Obtaining support from the national Ministry of Health. 3. Obtaining support from the provincial ministry of Jujuy and agreement on resource provision and health system reorganization. 4. Involvement of Jujuy second level health authorities and heads of services.

First, introduction of HPV-testing was approved by consensus by program managers and providers of the 24 Argentinean provinces ${ }^{24}$ during the program annual scientific seminar that also gathered international scientific leaders. Scientific evidence about HPV-test 
performance was presented and discussed in this meeting and was the basis for the decision to introduce the test. Thus, the National Program on Cervical Cancer Prevention (NPCCP) got a mandate from meeting participants to implement a demonstration project to introduce HPV-testing.

Secondly, the proposal was presented to national health authorities, which saw the JDP as an opportunity to show actions on women`s health as well as to increase visibility of the recently created National Cancer Institute. The national Ministry of Health approved the project and committed needed resources.

Once national support was guaranteed, the project was presented to the Jujuy Ministry of Health. A driving idea present in these initial discussions was the possibility of introducing a novel technology that would allow the provincial authorities to show actions and results to reduce the province high burden of cervical cancer. An agreement was signed between the national and provincial ministry of health, which included as key elements: Provision of tests and part of the treatment equipment by the national government, as well as communication materials and funding of specific human resources (data enters and patient navigators). The provincial ministry of health agreed with reorganizing health services as needed (i.e. laboratory centralization) and committing resources to achieve project goals (i.e. establishing cervical cancer screening a priority activity for Community Health Workers (CHWs).

Finally, specific activities were carried out to involve Jujuy second level health authorities and heads of services. Several meetings were carried out to explain the project, and to agree on goals, specific tasks and responsibilities. These latter were part of an agreement signed between the national and provincial Ministry of Health. ${ }^{25}$

\section{Partnerships for collaboration}

The JDP was established as a collaborative project between the national and provincial ministries of health, with active participation of key health departments (i.e. primary health care) and stakeholders at a very early stage of the design and planning process. 
Endorsement from the scientific medical community was secured through a Scientific Advisory Committee (SAC), with participation of the main national and provincial scientific societies, scientific institutions (i.e. Instituto Malbrán) and international agencies (i.e. IARC). SAC regularly met to discuss process results and strategies to overcome identified obstacles. Important consideration was given to inclusion of the cytology/pathology societies, as some concern was raised about opposition to the project by the health professionals in charge of Pap-smear reading.

\section{Regulation}

National guidelines were elaborated and updated through several steps: review of scientific evidence, consultancy with national and international experts, and approval by the SAC. ${ }^{14}$ A provincial "resolution" was enacted with the new protocol, establishing HPV-testing as the primary screening method in all public health centers.

\section{Policy guidance}

National/provincial health authorities signed an agreement on an annual screening uptake goal, established as a provincial public health priority. CHWs were monitored and evaluated in relation to how many of the women they usually visit were HPV-tested. CHW performance was regularly reported to the Minister of Health.

\section{Accountability}

The JDP regularly provided health authorities with feedback about project progress and several instances existed to monitor process indicators, discuss problems and possible solutions. A list with main identified problems during project implementation and proposed solutions is presented in table 3.

JDP intermediate results were presented in national and international scientific meetings and congresses. 
Table 3. Problems and agreed strategies implemented during JDP. Jujuy, 2012-2014

\begin{tabular}{|c|c|}
\hline Problem & Agreed strategy \\
\hline $\begin{array}{l}\text { Low screening uptake among } \\
\text { target population }\end{array}$ & Self-collection offered by CHWs with a nominated list. \\
\hline $\begin{array}{l}\text { Delays in delivery/distribution of } \\
\text { collectors }\end{array}$ & \\
\hline $\begin{array}{l}\text { Insufficient staff to enter data in } \\
\text { SITAM at the HPV laboratory }\end{array}$ & $\begin{array}{l}\text { Incorporation of data enter to the HPV laboratory } \\
\text { Data entry of test taking at health centers to reduce data entry burden at } \\
\text { the HPV laboratory }\end{array}$ \\
\hline $\begin{array}{l}\text { Difficulties in sending results to } \\
\text { health centers }\end{array}$ & $\begin{array}{l}\text { Printing of results at health centers using SITAM } \\
\text { Training of staff from health centers to use SITAM }\end{array}$ \\
\hline $\begin{array}{l}\text { Low adherence to follow up by } \\
\text { women HPV+/Cy- }\end{array}$ & $\begin{array}{l}\text { Elaboration of nominated list of these women to be distributed among PHC } \\
\text { supervisors and CHWs. Recommendation to contact these women } \\
\text { whenever possible. }\end{array}$ \\
\hline $\begin{array}{l}\text { Low adherence to triage by } \\
\text { women with positive HPV self- } \\
\text { collected tests }\end{array}$ & Active search of these women by CHWs \\
\hline $\begin{array}{l}\text { Differences in diagnostic criteria } \\
\text { of colposcopy units. }\end{array}$ & Refresher training of colposcopists \\
\hline Risk of expiration of HPV-tests & $\begin{array}{l}\text { Activities at community level to promote HPV testing } \\
\text { Promotion in local radios } \\
\text { Self-collection established as a priority service provision by CHWs (in } \\
\text { relation to other health issues) } \\
\text { Close monitoring of CHWs with low self-collected tests }\end{array}$ \\
\hline
\end{tabular}

\section{Organizational capacity}

\section{Service delivery and health workforce}

Jujuy health system includes a main hospital (Pablo Soria Hospital) and 300 primary health care (PHC) centers. The PHC System employs around 700 full-time CHWs who visit approximately 110,000 households twice yearly for health-related tasks such as immunization and maternal and child health promotion.

The existing offer of human resource at the public health system was evaluated and considered adequate. Services involved in the screening/diagnosis/treatment process were 
reorganized; main axis of this reorganization were intended to make improvements in the screening process that had been identified as inefficient components of the previous cytology-based screening, ${ }^{12}$ : Decentralization of cytology reading in small laboratories without quality control, lack of adherence to age and frequency screening recommendations, an informal network for sample transportation and sending of results, and use of colposcopy as a screening method. The following changes were made:

The need of a central cytology/biopsy/HPV laboratory implied centralization of cytology laboratories from three to one, and reassignment of human resources to the new central laboratory. A central cytology-histology-HPV laboratory was created at the Pablo Soria Hospital, under supervision of a pathologist. The purpose of this centralization was to assure high quality of laboratory processes, and facilitate quality control procedures and coordination between cytology, histology and HPV sections of the service. In addition, centralizing laboratories processes under the supervision of a pathologist was a strategic decision by the NPCCP to limit potential opposition of cytologists to HPV-test introduction in Argentina.

Also, a decision was made by the Chief of the Laboratory to not process HPV samples that did not comply with the established age range, frequency and follow-up algorithm. Women were informed through the sample taker the reason why their test was not analyzed; they were reminded of the protocol and date of next HPV-testing.

HPV sample has 14 days without the need of refrigeration; this characteristic facilitated reorganization of sample transport to the laboratory, establishing responsibilities at health centers for assuring transport at specified days. Samples arriving later than 14 days were rejected by the laboratory. Also, the system to send screening results to the health centers was reorganized: It was decided that printed results would no longer be sent to health centers, instead they would be downloaded from SITAM. All these decisions were supported by the NPCCP and provincial health authorities.

Screening was opportunistic, but several promotion activities were carried out involving CHWs and two mobile trailers. Education materials were disseminated and displayed at 
health institutions. A TV/radio campaign was broadcasted on local mass media (first year only), however an evaluation suggested that diffusion in TV/radio channels was insufficient and probably had little impact. ${ }^{26}$ Patient navigation was provided to women with HPV/abnormal cytology (ASCUS +) results.

In 2012, the EMA Project, ${ }^{7}$ a Randomized-controlled-trial to evaluate effectiveness of HPVself collection was embedded in the JDP. The trial was also a collaborative project between the national/provincial ministries and demonstrated four times more screening among women who had the option to perform self-collection. Based on results of the EMA Project, Programmatic HPV-self collection was introduced in $2014^{15}$ for under-screened women with public health insurance.

The referral network for triage/diagnosis/treatment was re-organized, after careful analysis of the capacity of each unit to respond to the estimated demand. In the case of colposcopy, calculation of that estimation was done considering that it would no longer be used as screening but as a diagnostic method of women with HPV-positive/abnormal Pap results. Annual meetings with colposcopists from the diagnostic network were carried out. These meetings served as refresher courses on colposcopy diagnosis and were also an opportunity to identify problems and obstacles to diagnosis. To increase women access to follow-up, a diagnosis unit was included in the provincial mobile trailer. In total 18

diagnostic centers and five treatment units provided services to women who need them. ${ }^{24}$

Training was provided to health providers from all involved services, i.e. sample takers, colposcopists, laboratory personnel, and data enters.

\section{Information}

A specific HPV module was added to SITAM, the information system for monitoring and evaluating screening activities ${ }^{27}$ an easy-to-use tool that displayed monitoring indicators at provincial, hospital and health center level. 


\section{Health care financing}

Funding of different component of the JDP was provided by the national and/or provincial ministries of health, and services were provided free of cost to women.

\section{Technology/strategy}

\section{Effectiveness}

International evidence on HPV-testing performance was a back bone of the project. It was the basis for the national regulation to introduce HPV-testing and was disseminated among health authorities and providers through several scientific meetings and seminars, with participation of national and international well-renowned scientists; which was key for increasing local knowledge and understanding about the methods.

There was wide acceptance among national leaders of the scientific/medical community about the effectiveness of HPV-testing and the need of changing the paradigm of cervical cancer screening. Several dissemination activities were carried out transfer this knowledge and understanding of the utility of the HPV-test to health providers. This was facilitated by participation of international agencies (i.e. IARC, PAHO) and well-renowned national institutions as the Instituto Malbrán, where it is located the Argentinean HPV-laboratory that is part of the WHO-HPV network. HPV-testing was part of what was called the comprehensive strategy to prevent cervical cancer in Argentina, including both HPV-testing and HPVvaccination, this latter introduced in 2011.

\section{Acceptability}

A key issue for acceptability of HPV-testing was the understanding of the advantages of HPVtesting in relation to cytology-based screening:

"We know that we are working with a test that is much more sensitive, less specific in regard to lesions, which means that it subsequently needs the PAP to complement it. 
However, it allows us to categorize as lower risk population nothing less than $87 \%$ of the population."

Acceptability was also linked to an idea that a health problem that had remained unchanged in the last decades could finally be solved by using a new technology:

"A new technique that breaks the 50-year-long paradigm of the PAP; to break, improve and update (...)."

"For us, everything was new too, and when something is new, it motivates because sometimes to motivate ourselves, to motivate the women, we need to have other tools. It's important to have something that isn't the same old procedure they've always known. This method has been very motivational for the teams and the women."

The HPV-test being an opportunity to produce improvements in the health system was also highly valued by the interviewees:

(...). It has been very useful, let's say, the test is multipurpose. It has been useful in what it's supposed to do and also has many parallel achievements such as quality control, saving time and money, and taking the resources to the population where it is really needed. In other words, it has many benefits."

Results of interviews showed that at health authority level, introduction of HPV-testing was seen as a way to focus on women health through a project that would allow health authorities to produce modifications in how the health system works.

"One objective of the ministry of health this year has been women's health, and we have seen that when we focus on a problem, we obtain good results. By focusing on it (cervical cancer prevention) we have changed the reality." 
Interviewees also manifested that HPV-introduction was facilitated by provincial normative regulation that established HPV-testing as primary screening, and support and guidance from the NPCCP:

A facilitator is (the fact that HPV-testing and self-collection) was introduced as a provincial norm, so HPV-testing can be provided as standard of care.

"A very good thing was the close support by the national team, which always reminded us what was the North in this project; because with the charge of work we have managing the health system, this guidance is very important for us, so the urgent does not make us miss the important things"

The possibility of using HPV-self collection was also seen as an opportunity for the health system to produce of huge change in women access to cervical cancer prevention:

"(..with HPV-self collection...) it is extraordinary to be able to reach a population group that rejects gynecological examination, or have no access to screening services."

In general, interviewees also manifested their desire of the JDP and self-collection will be continued as a health policy after project termination:

"We hope that this is a method that will go on and on for a very long time. We hope it doesn't end up being just a study, but that it be implemented as a state policy within the guidelines that state policies have within this provincial government: women's health (...).".

\section{Discussion}

The use of the HSF enabled us to identify key components of the JDP that were the policy and health system scenario that made possible the effective introduction of HPV-testing in Jujuy. Key components were the project political support, programmatic and health service reorganization, actions to assure accountability, local funding of project activities and providing services free of cost for women, availability of an information system, and high acceptability of the strategy by stakeholders. 
Stewardship refers to the policy environment in which the implementation of a health strategy is made possible, through three main dimensions: Formulating health policy, collecting and using intelligence, and regulation. ${ }^{21}$ Health systems from middle-low income countries are affected by substantial weaknesses in governance processes and structures, which specially affect control of chronic diseases. ${ }^{28}$ In addition, in contemporary health systems, the number of actors and institutions has multiplied and authorities deal with a highly complex policy process that can only be governed through processes of steering, coordination and goal-setting, and only by developing a wide range of tools and strategies to this end. 21,29 In the JDP several strategies were carried out to strengthen stewardship, including involvement of stakeholders in all phases of the project, and enacting of national and provincial norms that ensured that HPV-testing was introduced with a strategic-policy framework. Political support was built in a steppedwise manner, each phase facilitated the next level of support needed to advance the project, i.e. obtaining support and mandate to introduce HPV-testing from provincial managers provided a legitimacy basis involve national authorities; also, showing high level authorities agreement and committed resources was key to obtain involvement of Jujuy second level health authorities and health providers. In addition, the development of national guidelines and protocols with involvement of well-recognized international experts and institutions such as IARC-WHO strengthened project viability. Installation of the HPV-testing laboratory as part of a central cytology-pathology-HPV-testing was mainly based in organization criteria to assure high quality procedures, but it was also used as a strategy to limit opposition to the project by cytologists and pathologists.

Involvement of stakeholders from the planning stage of program implementation is needed to ensure that the necessary results will be obtained and that appropriate corrective measures will be applied as needed. ${ }^{30}$ In the JDP several activities were carried out to build consensus with key actors. ${ }^{24}$ National and provincial authorities signed formal agreements and established common objectives and goals. They also agreed on giving cervical cancer prevention priority in the political health agenda. Thus, activities were scheduled, and resources allocated accordingly.

In the JDP, protocols were elaborated together with the main scientific societies and institutions through a participatory process. Also, implementation of the strategy was carried out in a complex context that required of mechanisms to identify problems and solutions to overcome them. Round management tables and constant communication between national and provincial teams were key components of those mechanisms. Thus, the concepts of policy guidance, regulation and partnership for collaboration were closely related in the implementation of the strategy.

Monitoring and evaluation in any health program is conducted to ensure that processes and systems are developed and adhered to in such a way that the deliverables are of good quality and maximize the benefits to the target population. ${ }^{30}$ Existence of a national screening information system (SITAM) guaranteed availability of timely data about monitoring indicators throughout the whole project. SITAM also provided data input to inform decision makers about project evolution, to identify problems and to discuss solutions. The use of SITAM in the JDP is an example of evidence-based monitoring and 
evaluation process as an essential component of cervical cancer prevention programs. The possibility of a permanent monitoring using SITAM was key in the work carried out by the management round tables, as discussions were rooted in data and indicators produced by the information system. This underscores the link between stewardship and the availability of information systems for monitoring and evaluation, as accountability is dependent on the existence of data to measure the extent of programmatic problems and produce corrective actions.

In many low- and middle-income countries, an important portion of health care is financed through private payment by service users. ${ }^{28,31}$ Evidence has also showed that when financial protection is provided it is often limited to costs related to some components of care while excluding other which are also essential. The JDP was financed using regular national and provincial budget, with a health system that provides universal access to health care, assuring financial access to the screening, diagnosis and treatment process. This was an essential component of the JDP as cervical cancer disproportionally affects poor women. ${ }^{32}$

Implementation of HPV-testing in health systems imposing out-of-pocket expenses for health care will certainly result in a reduced effectiveness of the strategy to control the disease. The available funding not only influence the capacity to assure needed resources for the health system, but also indicate what is valued by that system. ${ }^{18}$ Thus, the decision by the national ministry of health to fund HPV-tests as well as other main project components such as training, communication materials, etc. might also have acted as a strong signal to the medical community of the high priority assigned to cervical cancer prevention.

The JDP was implemented in a setting where health infrastructure and human resources were evaluated as adequate. Diagnostic and treatment services were available, and reorganization was carried out in those components deemed inefficient or with poor quality. A treatment network was organized as well as a navigator program to provide support and reduce women's barriers to treatment. Doubtless access to treatment is a sine-qua-non condition to guarantee effectiveness of a screening program, and the high level of treatment ( $84 \%$ of women diagnosed with CIN2+) observed in the JDP was the result of extensive work carried to increase service availability and respond to women's needs. ${ }^{33}$

The JDP had a high acceptability by stakeholders, health services and providers, as $100 \%$ of provincial health centers and providers adopted the strategy, main scientific societies participated in the process of building algorithms and protocols with no opposition from any of them, including the national cytology and pathology societies. Results from the qualitative interviews showed that this high level of adoption was highly related to the effectiveness of the strategy, which was seen as a positive innovation.

Technology is one of the three drivers of an opportunity window to implement public policies. In the case of the JDP, this idea of a new, effective technology as an opportunity to improve inefficient components of the screening system was very present in the responses of the interviewees. In Argentina, cytologybased screening has been in place for more than 50 years, and although in the past some initiatives had been carried out to improve programmatic screening, they had little impact in program organization and outcomes. Acceptability was also linked to this possibility to modify the cervical cancer prevention status 
quo, and also, for health authorities and providers, to the possibility to show results on a disease that is considered as an indicator of poor women's health and gender inequality.

The fact that HPV-testing can be self-collect by women, was also an important component of the acceptability of the strategy. Self-collection was seen by stakeholders as a tool that gave the health system the possibility to reach a population that is usually out of reach and, in this way, produce a real change in the burden of the disease. During the third year of the JDP, self-collection represented almost $40 \%$ of total HPV-testing, and allowed for a significative increase of screening among socially vulnerable women. Self-collection was offered during home visits by $700 \mathrm{CHWs}$ that are part of the Jujuy Primary Health system; ${ }^{15}$ thus, full exploitation of the technology was facilitated by the existence of an extensive network of community agents that routinely visit households for provision of health services. Use of HPV self-collection at a large scale in other settings without such a network will be limited if no other strategies are developed to contact out of reach women who usually do not visit health centers.

Our study has several limitations: First, although blocks included in HSF are considered as a set of inputs that contribute to the desired outcomes of a health system, one of the limitations of the framework is that does not easily capture interaction between the blocks. ${ }^{34}$ We have tried to overcome this by identifying links between dimensions, as well as their dynamic interactions. Secondly, working at the Ministry of Health or involved in the design and implementation of cervical cancer prevention activities in Argentina, all researchers in this study participated in processes linked to the project under investigation. Such experiences allowed them to gather insights into the implementation process, but, at the same time, may have biased the description of narrated activities.

\section{Conclusion}

This analysis has made explicit the policy context in which the JDP was implemented, and system components that were key for the demonstrated effectiveness of the strategy, and its high level of reach and adoption. These are a high level of political support and consensus among stakeholders, the demonstrated effectiveness of the technology and its acceptability by health authorities and providers, funding of tests and diagnosis/treatment services, implementation of an information system for monitoring and evaluation, and the reorganization of the network of screening diagnosis and treatment services.

\section{List Of Abbreviations}

CIN2+: Cervical Intraepithelial Neoplasia grade 2 or worse.

CHWs: Community Health Workers.

HPV: Human Papilloma Virus.

HSF: Health System Framework. 
JDP: Jujuy Demonstration Project.

NPCCP: National Program on Cervical Cancer Prevention.

PHC: Primary Health Care.

SAC: Scientific Advisory Committee.

SITAM: Sistema de Información para el Tamizaje (National Screening Information System).

\section{Declarations}

\section{Ethics approval and consent to participate}

This protocol has been approved by the CEMIC Institutional Review Board (Protocol number 1186). A written informed consent was obtained from all participants in the study.

\section{Consent for publication}

Not applicable.

\section{Availability of data and material}

The datasets used in this study are available from the corresponding author on reasonable request.

\section{Competing interests}

The authors declare that they have no competing interests.

\section{Funding}

This paper presents independent research funded by the Argentinean National Cancer Institute and CONICET. The views expressed are those of the authors and not necessarily those of the Argentinean National Cancer Institute or CONICET.

\section{Authors' contributions}

SA originally conceived the study and secured research support. SA was the principal investigator and study coordinator. MP was the investigator in charge of monitoring and evaluation. RL made substantial contributions to the conception, design, and analysis of the study. LT made substantial contributions to study design and implementation. All authors were involved in interpretation of data and critical revision of the manuscript.

\section{Acknowledgements}


We would like to thank Cecilia Straw for conducting the interviews with health authorities, and interviewees for their time and cooperation.

\section{References}

1. Gustafsson, L, Pontén J, Bergström R, Adami HO. International incidence rates of invasive cervical cancer before cytological screening. Int J Cancer. 1997; 71: 159-165.

2. International Agency for Research on Cancer (IARC) - World Health Organization (WHO). IARC Handbook on Cervical Cancer Prevention. Volume 10. Cervix Cancer Screening. Lyon: IARC Press; 2005.

3. Lazcano-Ponce EC, Moss S, Alonso de Ruiz P, Salmerón Castro J, Hernández-Ávila MH. Cervical cancer screening in developing countries: Why is it ineffective? The case of Mexico. Arch Med Res. 1999; 30: 240-250.

4. Sankaranarayanan R, Budukh A, Rajkumar R. Effective screening programmes for cervical cancer in low- and middle-income developing countries. WHO Bulletin. 2001; 79:954-62.

5. Sankaranarayanan R, Nene BM, Shastri SS, Jayant K, Muwonge R, Budukh AM, et al. HPV screening for cervical cancer in rural India. N Engl J Med. 2009; 360: 1385-1394.

6. Verdoodt F, Jentschke M, Hillemanns P, Racey CS, Snijders PJ, Arbyn M. Reaching women who do not participate in the regular cervical cancer screening programme by offering self-sampling kits: a systematic review and meta-analysis of randomised trials. Eur J Cancer. 2015. doi: 10.1016/j.ejca.2015.07.006.

7. Arrossi S, Thouyaret L, Herrero R, Campanera A, Magdaleno A, Cuberli M, et al. Effect of selfcollection of HPV DNA offered by community health workers at home visits on uptake of screening for cervical cancer (the EMA study): a population-based cluster-randomised trial. Lancet Glob Health. 2015. doi: 10.1016/S2214-109X(14)70354-7. 
8. Sankaranarayanan R, Qiao YL, Keita N. The next steps in cervical screening. Women's Health (Lond). 2015 Mar;11(2):201-12. doi: 10.2217/whe.14.70.

9. Organización Panamericana de la Salud (OPS). Incorporación de la prueba del virus del papiloma humano en programas de prevención de cáncer cervicouterino. Manual para gerentes de programas de salud. Washington, DC: OPS ; 2016. https://www.paho.org/hq/index.php? option=com_docman\&view=download\&category_sl

10. Turner S, Goulding L, Denis JL, et al. Major system change: a management and organisational research perspective. In Raine R, Fitzpatrick R, Barratt $H$, Bevan G, Black N, Boaden R, et al. Challenges, solutions and future directions in the evaluation of service innovations in health care and public health. Health Serv Deliv Res 2016; 4 :85-104.

11. Arrossi S, Paolino M, Laudi R, Gago J, Campanera A, Marín O, Falcón C, Serra V, Herrero R, Thouyaret L. 2019. Programmatic human papillomavirus testing in cervical cancer prevention in the Jujuy Demonstration Project in Argentina: a population-based, before-and-after retrospective cohort study. Lancet Glob Health 7:e772-e783.Arrossi S. 2019. Access to treatment in the Jujuy Demonstration Project. Lancet Glob Health. 2019 Aug;7(8):e1015-e1016.

12. Arrossi S, Paolino M, Sankaranarayanan Challenges faced by cervical cancer prevention programs in developing countries: a situational analysis of program organization in Argentina. Rev Panam Salud Publica. 2010; 28: 249-257.

13. Rutter H, Savona N, Glonti K, et al.. The need for a complex systems model of evidence for public health. Lancet. 2017; 9:390(10112):2602-2604.

14. Arrossi S, Thouyaret L, Paul L. Prevención del cáncer cervicouterino. Recomendaciones para el tamizaje, seguimiento y tratamiento de mujeres en el marco de programas de tamizaje basados en el test de VPH. Actualización 2015. Buenos Aires: Instituto Nacional del Cáncer : 2015 
http://www.msal.gob.ar/images/stories/bes/graficos/0000000017cnt-

manual_recomendaciones_tamizaje_2015_baja.pdf accessed 20 July 2019.

15. Arrossi S, Paolino M, Thouyaret L, Laudi R, Campanera A. Evaluation of scaling-up of HPV selfcollection offered by community health workers at home visits to increase screening among socially vulnerable under-screened women in Jujuy Province, Argentina. Implement Sci. 2017. doi: 10.1186/s13012-017-0548-1.

16. World Health Organization (WHO). 2007. Everybody's Business: Strengthening Health System to Improve Health Outcomes, WHO's Framework for

Action. http://www.who.int/healthsystems/strategy/everybodys_business.pdf, accessed 19 July 2019.

17. Ettelt S, Hawkins $B$, and Alvarez-Rosete A. Analysing evidence use in national health policy-making an institutional approach. Working Paper \# 3. London School of Hygiene and Tropical Medicine, London, UK: 2013

18. Gilson L, editor. Health policy and systems research: a methodology reader. Geneva: World Health Organization: 2012

19. Yamey G.. Scaling up global health interventions: a proposed framework for success. PLoS Med. 2011; 8:e1001049.

20. Alliance for Cervical Cancer Prevention (ACCP). Planning and implementing cervical cancer prevention and control programs: a manual for managers. Seattle: ACCP: 2004.

21. Alvarez-Rosete A, Hawkins B, Parkhurst J. Health system stewardship and evidence informed health policy. In: Working Paper $\mathrm{N}^{\circ} 1$. London School of Hygiene and Tropical Medicine GRIP-Health Programme. London: GRIP-Health programme; 2013. 
22. Denzin, NK. \& Lincoln, YS. (Ed.). Collecting and interpreting qualitative materials. United States: Sage Publications; 2003.

23. Pinnock H, Barwick M, Carpenter C, Eldridge S, Grandes G, Griffiths CJ, Rycroft-Malone J, Meissner P, Murray E, Patel A, Sheikh A, Taylor SJC for the StaRI Group. Standards for Reporting Implementation Studies (StaRI) statement. BMJ 2017;356:i6795

24. Arrossi S, Thouyaret L, Laudi R, Marín O, Ramírez J, Paolino M, et al. Implementation of HPV-testing for cervical cancer screening in programmatic contexts: The Jujuy demonstration project in Argentina. Int J Cancer. 2015. doi: 10.1002/ijc.29530.

25. Ministerio de Salud de la Nación. Plan de Reducción de la Mortalidad Materno Infantil, de la Mujer y la Adolescente. Available from: http://www.msal.gob.ar/plan-reduccionmortalidad/pdfs/plan_operativo_reimpresion_junio2010_WEB.pdf acceded July 20, 2019.

26. Arrossi S, Cuberli M. Opiniones acerca de la primera campaña de comunicación pública sobre el test de VPH en la Argentina en Petracci M, Rodriguez Zoya G (comp). Comunicación y Salud. La investigación en el proceso de las políticas públicas, Teseo: Buenos Aires: 2018.

27. World Health Organization (WHO). Cervical cancer screening information system: Argentina. In: WHO Compendium of innovative health technologies for low-resource settings, 2011-2014. Assistive devices, eHealth solutions, Medical devices, Other technologies, Tecnologies for outbreaks. Geneva: WHO; 2015. pp.84.

28. Samb B, Desai N, Nishtar S, et al. Prevention and management of chronic disease: A litmus test for health-systems strengthening in low-income and middle-income countries. The Lancet 2010; 376: 1785-97. 
29. Saltman RB, Ferroussier-Davis O. The concept of stewardship in health policy. Bull World Health Organ 2000; 78:732-9.

30. World Health Organization (WHO). Comprehensive cervical cancer control: A guide to essential practice. 2 nd ed. Geneva: WHO; 2015.

31. Panamerican Health Organization (PAHO). Cervical cancer prevention and control programs: A rapid assessment in 12 countries of Latin America, Washington: 2012. https://www.paho.org/hq/dmdocuments/2012/PAHO-Cervical-Cancer-Prevention-2010.pdf accessed 19 July 2019.

32. Arrossi, S., Matos, E., Zengarini, N., Roth, B., Sankaranarayanan, R. y Parkin, M. The socio-economic impact of cervical cancer on patients and their families in Argentina, and its influence on radiotherapy compliance. Results from a cross-sectional study. Gynaecologic Oncology. 2007; 105(2):335-340.

33. Arrossi S. Access to treatment in the Jujuy Demonstration Project. Lancet Glob Health. 2019;7(8):e1015-e1016.

34. Mounier-Jack S, Griffiths UK, Closser S, Burchett H, Marchal B. Measuring the health systems impact of disease control programmes: A critical reflection on the WHO building blocks framework. BMC Public Health. 2014; 25; 14:278.

\section{Figures}




\section{HPV TESTING}

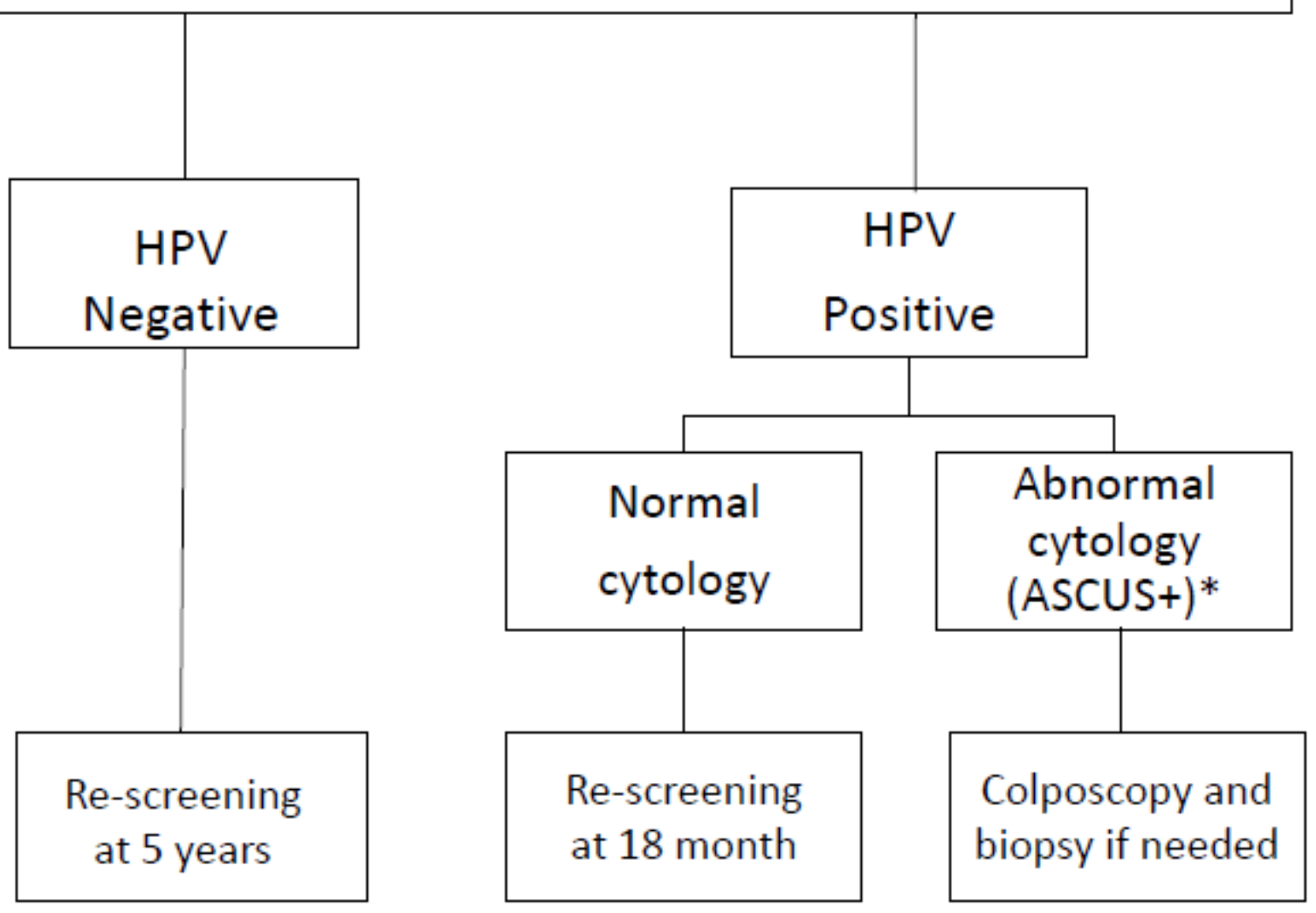

\section{Figure 1}

Cervical cancer screening algorithm for women aged 30+ with HPV testing * ASCUS+ includes: Atypical squamous cells of undetermined significance (ASC-US), Low-grade squamous intraepithelial lesion (LSIL); atypical squamous cells cannot exclude HSIL (ASC-H); High grade squamous intraepithelial lesion (HSIL); Atypical Glandular Cells (AGC) and Adenocarcinoma In Situ. 